\title{
In vitro Antiviral Activity of Recombinant Antibodies of IgG and IgA Isotypes to Hemagglutinin of the Influenza A Virus
}

\author{
V. V. Argentova ${ }^{a, *}$, T. K. Aliev ${ }^{b}$, V. V. Zarubaev ${ }^{c}$, S. A. Klotchenko ${ }^{c}$, A. A. Shtro ${ }^{c}$, \\ M. V. Sergeeva ${ }^{c}$, V. A. Toporova ${ }^{d}$, D. A. Dolgikh ${ }^{a, d}$, P. G. Sveshnikov ${ }^{e}$, \\ V. A. Vasin ${ }^{c}$, and M. P. Kirpichnikov ${ }^{a, d}$ \\ ${ }^{a}$ Department of Bioengineering, Faculty of Biology, Moscow State University, Moscow, 119234 Russia \\ ${ }^{b}$ Department of Chemical Enzymology, Faculty of Chemistry, Moscow State University, Moscow, 119991 Russia \\ ${ }^{c}$ Research Institute of Influenza, Ministry of Healthcare of the Russian Federation, St. Petersburg, 197376 Russia \\ ${ }^{d}$ Shemyakin-Ovchinnikov Institute of Bioorganic Chemistry, Russian Academy of Sciences, Moscow, 117997 Russia \\ ${ }^{e}$ Russian Research Center for Molecular Diagnostics and Therapy, Moscow, 117149 Russia \\ *e-mail: vicarg@rambler.ru
}

Received April 28, 2017; in final form, June 26, 2017

\begin{abstract}
Seasonal and highly infectious strains of the influenza A and influenza B viruses cause millions of cases of severe complications in elderly people, children, and patients with immune diseases each year. Immunoglobulin A (IgA), which is an active component of humoral immunity, can prevent the spread of the virus in the upper respiratory tract. The preparation and study of the properties of recombinant virus-specific IgA could be an important approach to finding new means of preventing and treating influenza. Based on CHO DG44 cells, we developed stable monoclonal cell lines that produce monomeric and dimeric antibodies FI6-IgA1 and FI6-IgA2m1 to hemagglutinin (HA) of the influenza A virus. When studying the productivity, growth, and stability of the obtained clones, we found that the dimeric form of antibodies of IgA1 isotype is superior to other forms. The dimeric form of IgA antibodies plays a key role in mucosal immunity. Recognizing the prospects of using dimeric IgA as prophylactic and therapeutic mucosal drugs for viral infections, we studied their virus-neutralizing and antiviral activities on MDCK cell culture and compared them with the antibodies of the IgG1 isotype. This study presents the data on antiviral and virus-neutralizing activities of the FI6-IgA1 dimers to seasonal and highly infectious strains of influenza A virus.
\end{abstract}

Keywords: influenza A virus, stable cell lines, IgG1, IgA2, dimeric IgA1, antiviral activity

DOI: $10.1134 / \mathrm{S} 0026893317060024$

\section{INTRODUCTION}

The development of new antibodies for the treatment of cancer and autoimmune diseases and for the protection against various pathogens is an important direction of research in modern fundamental and applied biomedicine. Although all clinically approved monoclonal antibodies (mAbs) belong to the $G$ class of immunoglobulins ( $\mathrm{IgG}$ ), studies on the production and functioning of the class A recombinant immunoglobulins deserve special attention.

IgA is the largest class of human immunoglobulins. It plays the key role in the activation of immunity in mucous membranes, which are the main primary pathways by which many infectious pathogens enter a human body. The binding of $\operatorname{IgA}$ to bacteria and viruses results in the neutralization of pathogens and prevents their attachment to mucosal cells, thus inhib-

Abbreviations: mAbs, monoclonal antibodies; RHA, hemagglutination reaction; sIgA, secretory $\operatorname{IgA}$. iting the infection. Much attention has recently been focused on the advancement of the production of recombinant IgA and their use as potential anti-infectious agents.

Immunoglobulin A is heterogeneous at the molecular level and has two isotypes, i.e., $\operatorname{IgA} 1$ and $\operatorname{IgA} 2$, which can form dimers by interacting with the joining chain $(\mathrm{J})$ or produce secretory $\operatorname{IgA}(\mathrm{sIgA})$ with the participation of the secretory component. sIgA protects immunoglobulin from degradation under the action of proteolytic enzymes; it enables IgA to function under severe conditions of the gastrointestinal tract, provides protection against infection in the mucous membranes [1], and can also slow the inflammatory effects of other immunoglobulins [2].

All immunoglobulins are glycoproteins that contain at least one $\mathrm{N}$-glycan. The glycosylation level of $\operatorname{IgA}$ is much higher than of $\mathrm{IgG}$. The presence of a large glycan part on both heavy chains of $\operatorname{IgA}(\mathrm{Fc} \alpha)$ determines their inhibitory effect on a pathogen's 
attachment to a host cell and the replication of a virus in infected epithelial cells. Depending on the isotype of $\operatorname{IgA}$, a molecule of human IgA can contain two to five glycosylation sites. The heavy chain of IgAl contains three $\mathrm{N}$-glycosylation sites; one is located in the $\mathrm{C}_{\mathrm{H}} 2$-domain and two are at the end of the $\mathrm{C}_{\mathrm{H}} 3$-domain [3]. There are reports on the glycosylation of variable domains of certain IgA [4]. The formation of the dimeric form of IgA depends on the position of $\mathrm{N}$-glycane, which provides the correct conformation of the $\mathbf{J}$ chain. The dimers can then form $\operatorname{sIgA}$, which contains seven more $\mathrm{N}$-glycans involved in its anchoring on the epithelial surface of mucous membranes. The fact that IgA antibodies contain $\mathrm{N}$ - and $\mathrm{O}$-glycosylation sites imposes certain limitations on the selection of systems for their production. For instance, unlike IgA2, an IgA1 molecule contains a mobile region with $\mathrm{O}$-linked glycans, the number of which can vary from three to five, whereas the IgA2 molecule contains no O-glycosylation sites [5].

It should be noted that the dimeric form of $\operatorname{IgA}$ is tetravalent. This feature sets it apart from bivalent IgG antibodies. In contrast with the monomeric forms of IgA and IgG, IgA dimers can be actively transported through the epithelial cell layer to serous surfaces.

Hemagglutinin glycoprotein (HA) is localized on the surface of the virion of the influenza A virus and involved in the initial stage of its infectious cycle. HA is the main influenza virus antigen, against which antibodies are produced during the immune response to the influenza infection and vaccination. Anti-HA antibodies can neutralize influenza virus and prevent the infection. However, their specificity is limited to a certain antigenic subtype of HA (type-specific antibodies) or even to a certain strain (strain-specific antibodies) of the influenza virus. HA of the influenza A virus has 16 different antigenic subtypes, which are combined into two large phylogenetic groups. Phylogenetic group I contains $\mathrm{H} 1, \mathrm{H} 2, \mathrm{H} 5, \mathrm{H} 6, \mathrm{H} 8, \mathrm{H} 9$, H11-13, and H16 subtypes, whereas the phylogenetic group II contains subtypes H3, H4, H7, H10, H14, and H15. Vaccination results in the predominant induction of strain-specific antibodies. A viral infection mostly induces the production of cross-reactive type-specific antibodies. In rare cases, mAbs that are cross specific to multiple subtypes of HA from a single phylogenetic group (I or II) can be isolated from people or laboratory animals who have recovered from the disease [6]. These antibodies are a platform for developing therapeutic drugs against a wide range of influenza A viruses.

The influenza A and B viruses are mainly have aerosol transmission and mucous membranes of the respiratory tract are entry sites of these viruses. It has been shown that the high efficiency of live vaccines in preventing influenza infection is primarily associated with the stimulation of the production of IgA class antibodies, which can penetrate mucous membranes of the respiratory tract and remain in the membranes for a long time $[7,8]$. In the trials of the vaccine developed and applied (since 2003) in the United States, it has been found that protection from the influenza virus infection correlates with the level of HA-specific sIgA in nasal lavage and not with the IgG antibody titer in blood serum [9-11]. Thus, the intranasal or inhalational administration of therapeutic IgA antibodies would be preferable because it would make it possible to deliver the drug to the primary infection area.

IgA antibodies are usually present in mucosal tissues as dimers, whereas IgG antibodies are in the monomeric form. In contrast with the IgA and IgG monomers, the $\operatorname{IgA}$ dimers bind to the polymeric immunoglobulin receptor (pIgR), which transports them from the basolateral to the apical part of the epithelium. This is how the IgA dimers enter secretions, where they function as antibodies [12]. The IgA dimers are also effective in initiating the antibodydependent cellular cytotoxicity (antibody-dependent cell cytotoxicity, ADCC). It is important that the effector activity of the IgA dimers is higher in the direct blockade of the epidermal growth factor receptor (EGFR), decreasing its modulation, and in inhibiting its growth than the IgA or IgG monomers.

In this work, we focused on the study of recombinant broad-specificity IgA antibodies, which may play a major role in developing protection against a wide variety of different subtypes of influenza A viruses. As an object of research, we used well-known neutralizing FI6 mAbs to HA of the influenza A virus. It has been previously shown that FI6 specifically binds to all 16 subtypes of HA and neutralizes influenza A viruses of two phylogenetically different groups (I and II) [13]. Based on the FI6 antibody, we have previously obtained recombinant mAbs to HA of the influenza A virus in the form of monomers and dimers of IgA [14]. In this work, we studied their antiviral activity to different strains of the influenza A virus. For comparison, we used the FI6 antibodies of the IgG1 isotype. Studies on the antiviral and virus-neutralizing activity of recombinant mAbs were performed in MDCK cell culture. In this culture, dimers of IgA1 mAbs efficiently inhibit the replication of the studied strains of the influenza A virus.

\section{EXPERIMENTAL}

Cell lines and conditions of cultivation. The Chinese hamster ovary cell line CHO DG44 (dhfr-) (Thermo Fisher Scientific, United States) was used in this study. The following media were used for its cultivation: the complete serum-free medium OptiCHO (Invitrogen, United States) with $200 \mathrm{mM}$ L-glutamine (Gibco, United States) and 10\% Pluronic F68 (Gibco) and the IMDM medium (Gibco) containing $10 \%$ dialyzed fetal bovine serum (DFBS; Gibco). We used antibiotic-antimycotic and gentamicin (Gibco). The culture 
was grown in a $\mathrm{CO}_{2}$ incubator at $8 \% \mathrm{CO}_{2}, 96 \%$ relative humidity, and $37^{\circ} \mathrm{C}$.

Normal Madin Darby canine kidney cells (MDCK; ATCC, \#CCL-34, United States) were plated in a 96-well plate in the amount of $10^{4}$ cells per well in $100 \mathrm{~mL}$ complete alpha-MEM medium (Eagle's minimal essential medium, Gibco) that contained $2 \mathrm{mM}$ L-glutamine (Gibco), $200 \mu \mathrm{g} / \mathrm{mL}$ ciprofloxacin (Sigma), and $10 \%$ fetal bovine serum (PAA, Austria). The incubation was performed in a $\mathrm{CO}_{2}$ incubator at $37^{\circ} \mathrm{C}$ and $5 \% \mathrm{CO}_{2}$ for $24 \mathrm{~h}$. Right before the experiment, the cells were washed with alpha-MEM medium. Subsequent manipulations were performed directly in supporting alpha-MEM medium that contained $200 \mu \mathrm{g} / \mathrm{mL}$ ciprofloxacin and $1 \mu \mathrm{g} / \mathrm{mL}$ trypsin (Sigma, United States).

Transfection. The transfection of the CHO DG44 (dhfr-) host cell line and the resulting stable cell lines that produce monomeric IgA antibodies was performed using the Lipofectamine 3000 reagent (Invitrogen, United States) according to the standard manufacturer's protocol. The concentration of cells and their viability were determined in a Goryaev's chamber using $0.04 \%$ trypan blue solution.

For transfection, we used previously obtained recombinant bipromotor plasmids pBiPr-ABIgA1FI6-ht and pBiPr-ABIgA2m1FI6-ht with unidirectional transcription of genes of the heavy and light chains of the FI6 human antibody to HA of the influenza virus. These plasmids contain the nucleotide sequence of the variable domains of the light and heavy chains of the antibody FI6 and differ by the constant domains of the heavy chain. Antibodies of the $\operatorname{IgA} 1$ and $\operatorname{IgA} 2 \mathrm{~m} 1$ isotypes, respectively, are expressed from these plasmids. To obtain the dimeric forms of IgA, the pcDNA-J plasmid was constructed as follows; it contains the gene of the J-chain, which links monomers to form dimers, and the G418 (gentamycin) resistance gene $[14,15]$.

Plasmid DNA was linearized with the Ple19I restriction enzyme to ensure stable transfection (SibEnzyme, Russia).

Enzyme-linked immunosorbent assay (ELISA). The level of $\operatorname{IgA}$ expression in the cell culture was determined by indirect ELISA. Mouse mAbs to light kappa-type chains of human immunoglobulins (Bialexa, Russia) were added to wells of a 96-well plate in the amount of $0.5 \mu \mathrm{g}$ per well. In the analysis, we used $\alpha$-chain-specific anti-human IgA antibodies (Sigma) conjugated to horseradish peroxidase. IgA from human serum (Sigma) were used as the standard.

Isolation of recombinant antibodies. Cell cultures that produce recombinant antibodies were grown in spinner flasks with a working volume of $500 \mathrm{~mL}$. The CD OptiCHO medium $(300 \mathrm{~mL}$; Invitrogen, United States) with standard additives was supplied with $(2.5-3.0) \times 10^{5}$ cells $/ \mathrm{mL}$. The cell culture was grown for 14-18 days in a $\mathrm{CO}_{2}$ incubator at $8 \% \mathrm{CO}_{2}$ and $37^{\circ} \mathrm{C}$ in glass spinner flasks at the impeller speed of 50-70 rpm.

The culture liquid was centrifuged at $400 \mathrm{~g}$ and concentrated by tangential filtration using a Vivaflow 50 cell (Sartorius AG, Germany) to $50-100 \mathrm{~mL}$. The resulting concentrate was dialyzed against phosphatebuffered saline, pH 7.4 (PBS). Affinity chromatography of the antibodies was performed according to the manufacturer's instructions. MabSelect columns were used to isolate IgG antibodies; HiTrap KappaSelect (GE Healthcare, United States), IgA antibodies. The resulting eluates were dialyzed against PBS.

The antibody concentration was determined spectrophotometrically by absorption at $280 \mathrm{~nm}$ on a NanoPhotometer P200 (Implen GmbH, Germany). For cell culture experiments, antibody samples were presterilized on cellulose-acetate filters with a pore diameter of $0.22 \mu \mathrm{m}$ (CA Syringefilter $26 \mathrm{~mm}$; Corning, United States).

Assessment of the toxicity of test substances in cell culture. The toxicity of compounds was assessed by cell viability in the reduction of the tetrazolium dye 3-(4,5-dimethylthiazol-2-yl)-2,5-diphenyl-2H-tetrazolium bromide (MTT). The staining intensity of the culture reflects its cell viability via the MTT reduction by mitochondrial and partially cytoplasmic dehydrogenases [16]. Each well of a plate was supplied with $100 \mu \mathrm{L}$ of the MTT solution $(0.5 \mathrm{mg} / \mathrm{mL}$ PBS $)$. Cells were incubated at $37^{\circ} \mathrm{C}$ and $5 \% \mathrm{CO}_{2}$ for $2 \mathrm{~h}$ and then washed with PBS for 5 minutes. The resulting precipitate was dissolved in $100 \mu \mathrm{L}$ of dimethylsulfoxide (DMSO) and the optical density of the solution was measured on a Victor 1420 plate analyzer (PerkinElmer, Finland) at $535 \mathrm{~nm}$. Based on the obtained data, we calculated the half-maximal cytotoxic concentration $\left(\mathrm{CC}_{50}\right)$, i.e., the compound concentration at which the optical density in the well decreases by half compared with the control cells without the compound.

Antibody preparations were dialyzed against the SGM buffer ( $40 \mathrm{mM}$ sodium succinate, $5 \mathrm{mM}$ glycine, $6 \%$ mannitol, $\mathrm{pH}$ 6.0). Anti-human TNF- $\alpha$ IgG1 antibodies (Infliximab ${ }^{\circledR}$ produced at the State Research Institute of Highly Pure Biopreparations of the Federal Medical and Biological Agency of Russia, Russia) were used as the negative control. Oseltamivir carboxylate (Tamiflu ${ }^{\circledR}$ manufactured by Hoffman-LaRoche, Switzerland), which is a specific inhibitor of the neuraminidase of influenza virus that effectively suppresses the replication of the virus, was the reference substance.

Influenza viruses. The following influenza virus strains were used in this study: A/California/07/09 (H1N1)pdm09 (CDC, United States) and A/Aichi/2/68 (H3N2), A/PuertoRico/8/34 (H1N1), A/mallard/ Pennsylvania/10218/84 (H5N2), A/Anhui/1/13 (H7N9), and B/Malaysia/2506/04 (Research Insti- 
tute of Influenza, Ministry of Healthcare of the Russian Federation, Russia).

Analysis of the antiviral activity of antibodies. The antiviral activity of recombinant mAbs was assessed by their ability to inhibit the replication of influenza virus in MDCK cells. Test samples of antibodies were diluted in the maintenance medium to the concentrations of $0.1-100 \mu \mathrm{g} / \mathrm{mL}$ and added as $100-\mu \mathrm{L}$ aliquots to the wells of 96 -well plates containing a monolayer of MDCK cells. The plates were incubated at $5 \% \mathrm{CO}_{2}$ and $37^{\circ} \mathrm{C}$ for $1 \mathrm{~h}$, after which each well was supplied with $100 \mu \mathrm{L}$ of the maintenance medium containing one of the series of tenfold dilutions of the virus $\left(10^{-2}-10^{-7}\right)$. The plates were then incubated at $5 \% \mathrm{CO}_{2}$ and $37^{\circ} \mathrm{C}$ for $48 \mathrm{~h}$.

The content of the virus in each cell was determined in the hemagglutination reaction (HAR) with a $0.5 \%$ suspension of chicken red blood cells. The virus titer was calculated by the method of L.J. Reed and $H$. Muench [17] and expressed in decimal logarithms of the median tissue culture infective dose $\left(\log \mathrm{TCID}_{50}\right)$. The antiviral activity of antibodies was evaluated by the reduction of the infectious activity of the virus in antibody-containing wells relative to that in control wells (without antibodies). All samples were analyzed in duplicate.

Analysis of the virus-neutralizing activity of antibodies. The virus-neutralizing activity of antibodies was evaluated by their ability to inhibit the infection of MDCK cells with the A/PuertoRico/8/34 influenza. Two-fold dilutions of the antibodies (starting with $100 \mu \mathrm{g} / \mathrm{mL}$ ) were prepared in $200 \mu \mathrm{L}$ of the maintenance medium. The resulting dilutions were supplied with $200 \mu \mathrm{L}$ of the maintenance medium containing the influenza virus at a concentration of $100 \times\left(\mathrm{TCID}_{50} / 50 \mu \mathrm{L}\right)$. The resulting samples were incubated for $1 \mathrm{~h}$ at room temperature, then applied to a monolayer of MDCK cells $\left(100 \mu \mathrm{L}\right.$ per well) and incubated at $37^{\circ} \mathrm{C}$ and $5 \% \mathrm{CO}_{2}$ for 3 days. Four wells were used for each dilution. The virus content in the wells was evaluated in the HAR; the absence of hemagglutination meant that the virus was completely neutralized by the antibodies. The antibody concentration that corresponds to the neutralization of the virus in $50 \%$ of the wells was calculated by the method of L.J. Reed and H. Muench [17].

Immunoenzymatic analysis of mAbs binding to MDCK cells infected with influenza virus on cell surface (cell-ELISA). A monolayer of MDCK cells infected with various influenza A viruses was used to evaluate the specificity of antibody binding. A monolayer of uninfected cells was used as a negative control (background nonspecific binding). Before the experiment, part of a 96-well plate with a monolayer of MDCK cells was infected with influenza virus at a dose of $0.5 \times\left(\mathrm{TCID}_{50} /\right.$ cell $)$ in alpha-MEM medium containing ciprofloxacin $(200 \mu \mathrm{g} / \mathrm{mL})$ and trypsin $(1 \mu \mathrm{g} / \mathrm{mL})$. After $20 \mathrm{~h}$, both infected and uninfected cells were washed with PBS, fixed with $4 \%$ paraformaldehyde in
PBS $(50 \mu \mathrm{L} /$ well $)$, and stored at $4{ }^{\circ} \mathrm{C}$. For cell- ELISA, the plates with fixed cells were blocked with $3 \%$ BSA (Amresco, United States) in PBS for $1 \mathrm{~h}$ at room temperature, then washed with PBST-PBS containing $0.1 \%$ Tween-20 (Serva, Germany). Twofold dilutions of antibodies (starting with $1 \mu \mathrm{g} / \mathrm{mL}$ ) in the blocking buffer were prepared, added to the plate wells $(100 \mu \mathrm{L} /$ well $)$, and incubated for $1 \mathrm{~h}$ at room temperature. The plate was washed, supplied with the respective horseradish peroxidase-labeled antibodies against human $\operatorname{IgA}$ and $\mathrm{IgG}$, incubated for $1 \mathrm{~h}$ at room temperature, and washed again. The solution of TMB (BD Biosciences, Unites States), which is horseradish peroxidase substrate, was added to the wells in an amount of $100 \mu \mathrm{L}$ and incubated for $15 \mathrm{~min}$ at room temperature. The reaction was then stopped by adding $50 \mu \mathrm{L}$ of $2 \mathrm{~N} \mathrm{H}_{2} \mathrm{SO}_{4}$ solution per well. The optical density of the solution in the wells was determined at $450 \mathrm{~nm}$ on an Imark plate spectrophotometer (BioRad, United States). The specificity of antibody binding was evaluated from the difference of the optical densities (ODs) in the wells containing the infected cells and in the control wells. Obtained data were presented graphically as a dependence of the optical density on the concentration of antibodies.

Data analysis. The values of $\mathrm{CC}_{50}$ and $\mathrm{IC}_{50}$ were calculated by analyzing the dependence of the infectious activity $\left(\log \mathrm{TCID}_{50}\right)$ on the antibody concentration calculated by nonlinear regression analysis performed using the Graph Pad Prizm software package [18]. The selectivity index (SI) was calculated as the ratio of $\mathrm{CC}_{50}$ to $\mathrm{IC}_{50}$.

\section{RESULTS}

\section{Preparation of Recombinant Stable Cell Lines That Produce FI6-IgA1 and FI6-IgA2m 1}

At the first stage, using the pBiPr-ABIgA1FI6-ht and $\mathrm{pBiPr}-\mathrm{ABIgA} 2 \mathrm{~m} 1 \mathrm{FI} 6$-ht bipromotor plasmids, we obtained clones that are superproducers of the monomeric forms of FI6-IgA antibodies to HA of the influenza A virus. To obtain the dimeric form of $\operatorname{IgA}$, we used previously obtained cell lines of superproducers of FI6-IgA1 and FI6-IgA2m1 antibody monomers with the highest level of expression of anti-influenza IgA monomers.

CHO DG44 suspension cells were transfected with a bipromotor plasmid containing heavy and light chain genes of the FI6 antibody. Highly productive clones were selected during screening performed on a ClonePix device (Molecular Devices Ltd., United Kingdom) using FITC-labeled antibodies against human IgA (Russian Research Center for Molecular Diagnostics and Therapy, Russia). The resulting cell lines, which are superproducers of FI6-IgA1 and FI6-IgA2m1 antibodies, were used for the subsequent transfection with the pcDNA-J plasmid containing the gene of the J-chain, which is necessary for the formation of dimers, and 


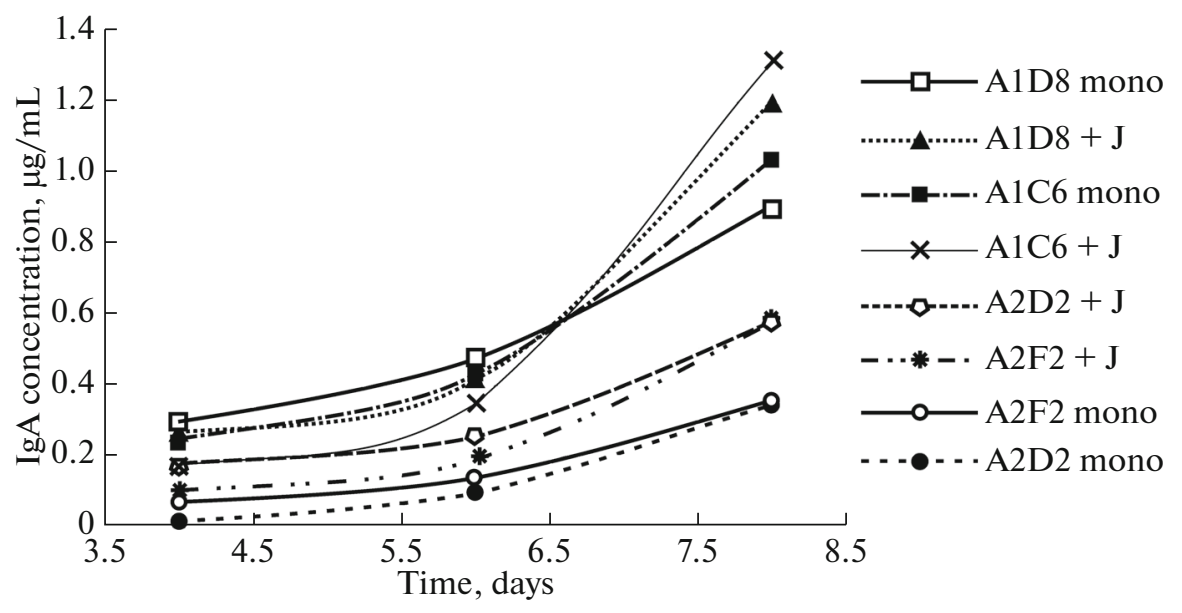

Fig. 1. Expression of IgA by different clones that produce monomeric and dimeric forms of FI6-IgA. Clones: A1D8 mono and A1C6 mono produce FI6-IgA1 monomers; A2D2 mono and A2F2 mono produce the FI6-IgA2m1 monomers; A1D8 + J and $\mathrm{A} 1 \mathrm{C} 6+\mathbf{J}$ produce the FI6-IgA1 dimers; and A2D2 + J and A2F2 + J produce the FI6-IgA2m1 dimers. Static cultures were grown in six-well plates under standard conditions.

the gentamicin $(G 418)$ resistance gene. In both cases, Lipofectamine 3000 was used as a transfection agent. Clones were grown on $\mathrm{CD}$ OptiCHO selective medium with the addition of the G418 antibiotic for the selection of clones that produce dimers of the FI6IgA1 and FI6-IgA2m1 antibodies with the J-chain. After the completion of the selection stage, a second screening was performed on a ClonePix device using FITC-labeled anti-human IgA antibodies to identify the most productive clones. The selected clones underwent additional selection by the method of limiting dilution to increase their productivity and stability.

\section{Comparison of the Expression of Monomeric and Dimeric Forms of IgA1 and IgA2 Isotypes}

Using the static culture method in six-well plates, the clones that produce dimeric FI6-IgA1 and FI6IgA2 $\mathrm{m} 1$ antibodies were obtained as described above and compared with analogous clones that produce monomeric IgA antibodies. The productivity was determined by ELISA. It was shown that the clones that produce the dimeric FI6-IgA1 and FI6-IgA2m1 antibodies have higher productivity than clones that produce monomeric antibodies. For instance, the productivity of the clones of the dimeric IgA1 antibodies is $28-38 \%$ higher and the productivity of the clones of the dimeric IgA2m1 antibodies is $45-47 \%$ higher than clones that produce monomeric antibodies of the respective isotypes (Fig. 1).

Stepwise selection on methotrexate was used to increase the productivity of the cell lines. Suspension cell cultures of the producers of dimeric forms of $\operatorname{IgA}$ were characterized by dynamic growth, the high viable cell density, and the ability to grow for prolonged time periods and retain high productivity for more than 20 days that was achived in batch culture in spinner flasks. In contrast, the time of growth of the producers of IgA monomers did not exceed 10-13 days (Fig. 2).

Unlike the producers of the IgA2m1 isotype dimers, cell cultures that produce the dimeric IgA1isotype antibodies did not form cell aggregates.

Based on the clone productivity data, a monoclonal stable cell line (clone dA1C6 $+\mathrm{J}$ ) that produced the dimeric FI6-IgAlantibodies was chosen for further experiments. Recombinant FI6-IgG1 antibodies and FI6-IgA1 dimers were isolated from the culture medium. The identity of the FI6-IgA1 dimers was determined by immunoblotting using goat anti-J-chain antibodies conjugated with horseradish peroxidase.

\section{Analysis of the Toxicity of the Antibodies}

To determine the range of working concentrations for the obtained FI6-IgG1 antibodies and the FI6IgA1 dimers, we evaluated their toxicity. The drug oseltamivir, which is an inhibitor of the influenza neuraminidase, was used as a control because all influenza virus strains were sensitive to this drug. Infliximab (anti-TNF $\alpha$-IgG1) was used as a negative control. The results of the experiment are shown in Table 1. The data shows that all tested samples of the antibodies are nontoxic over the entire range of the studied concentrations.

\section{Antiviral Activity of the Antibodies}

As follows from the data presented in Table 2, FI6IgG1 antibodies and FI6-IgA1 dimers inhibited different influenza viruses to a varying extent. The A/California/07/09 (H1N1)pdm09, A/mallard/ Pennsylvania/10218/84 (H5N2), and A/PuertoRico/ 8/34 (H1N1) influenza strains turned out to be most sensitive to the antibodies. For these strains, the $\mathrm{IC}_{50}$ 


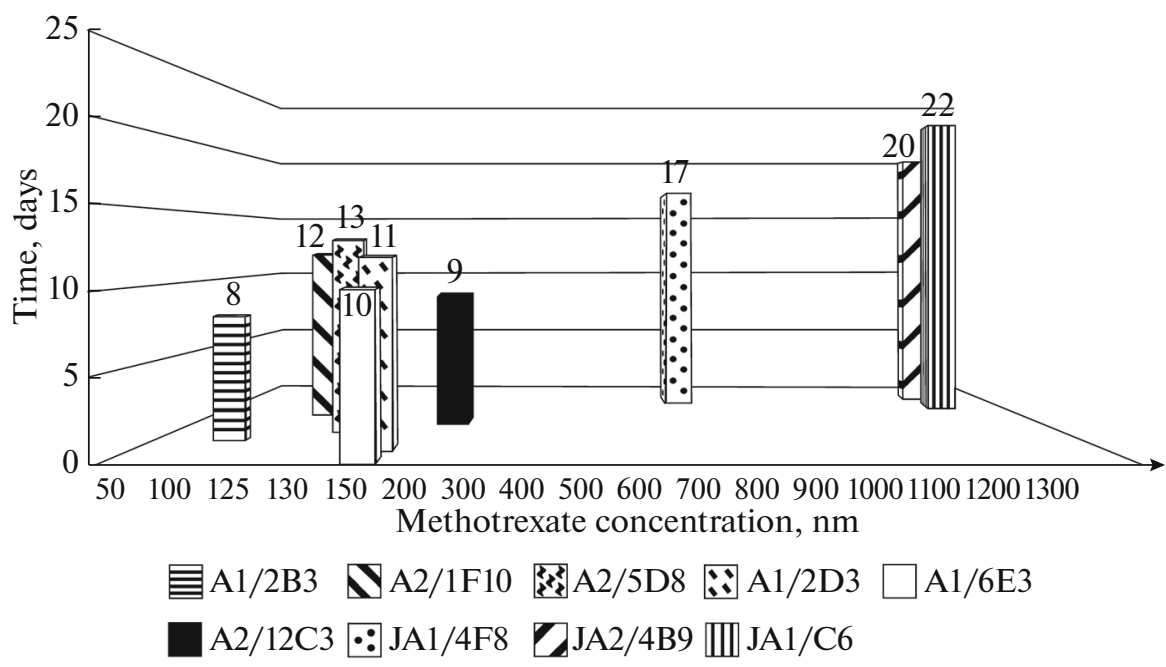

Fig. 2. Comparison of the growth of stable cell lines producing monomeric and dimeric forms of $\operatorname{IgA} 1$ and IgA2m1 in spinner flasks. MTX is methotrexate. Clones A1/2D8, A1/6E3, and A1/2B3 produce the FI6-IgA1 monomers; A2/5D8, A2/12C3, and A2/1F10 produce the FI6-IgA2m1 monomers; JA1/4F8 and JA1/C6 produce the FI6-IgA1 dimers; and JA2/4B9 produces the FI6- $\operatorname{IgA} 2 \mathrm{~m} 1$ dimer.

values for FI6-IgG1 antibodies were $0.25,0.1$, and $0.1 \mu \mathrm{g} / \mathrm{mL}$, while the SI values were 400,1000 , and 1000 . For the FI6-IgA1 dimers, the $\mathrm{IC}_{50}$ values were almost similar $(0.5,0.1$, and $0.5 \mu \mathrm{g} / \mathrm{mL}$, respectively) and the SI values were 200,1000 , and 200 , respectively. However, the A/Aichi/2/68 (H3N2), A/Anhui/1/13 (H7N9), and B/Malaysia/2506/04 influenza viruses were almost insensitive to the action of the antibodies. The $\mathrm{IC}_{50}$ values for the antibodies FI6-IgG1 and FI6IgA1 were $100 \mu \mathrm{g} / \mathrm{mL}$ and the SI values were equal to 1 for all three viruses. Anti-TNF $\alpha-\operatorname{IgG} 1$ antibodies, which were used as the negative control, showed no activity against any of the influenza virus strains that we studied.

The SI values that characterize the activity of the FI6-IgG1 antibodies and FI6-IgA1 dimers against different strains were compared with the corresponding parameters for oseltamivir carboxylate (see Table 3).

The reference preparation (oseltamivir carboxylate) efficiently inhibited the reproduction of all stud- ied viruses and the obtained IC50 and SI values were in agreement with the literature data [19-21]. Unlike oseltamivir, the antibodies exerted selective action against influenza viruses; they mostly suppressed influenza A viruses of the phylogenetic group I.

\section{Virus-Neutralizing Activity of the Antibodies}

Antibodies that have neutralizing activity against influenza viruses play an important role in preventing the development of influenza infection. The neutralizing activity of FI6-IgG1 antibodies and FI6-IgA1 dimers was studied using the A/Puerto Rico/8/34 (H1N1) influenza virus. Both antibodies equally inhibited the infection of cells with the virus. The calculated half-maximal inhibitory concentration was $17.85 \mu \mathrm{g} / \mathrm{mL}$; this value nearly coincides with the value published for the parent FI6 antibody [13]. Based on these data, it can be concluded that the functional

Table 1. Analysis of the toxicity of FI6-IgG1 antibodies and FI6-IgA1 dimer in MDCK cell culture

\begin{tabular}{c|c|c|c|c}
\hline \multirow{2}{*}{ Concentration, $\mu \mathrm{g} / \mathrm{L}$} & \multicolumn{4}{|c}{ Optical density $\left(\mathrm{OD}_{535} \times 10^{3}\right)$ in MTT test } \\
\cline { 2 - 5 } & FI6-IgG1 & FI6-IgA1 dimer & infliximab & oseltamivir carboxylate \\
\hline 100 & $487 \pm 15$ & $465 \pm 14$ & $485 \pm 10$ & $458 \pm 23$ \\
30 & $436 \pm 9$ & $462 \pm 8$ & $435 \pm 13$ & $423 \pm 11$ \\
10 & $425 \pm 11$ & $453 \pm 12$ & $457 \pm 12$ & $435 \pm 3$ \\
3 & $500 \pm 12$ & $475 \pm 11$ & $468 \pm 14$ & $428 \pm 5$ \\
1 & $485 \pm 8$ & $454 \pm 8$ & $472 \pm 8$ & $438 \pm 9$ \\
0.3 & $476 \pm 7$ & $495 \pm 10$ & $465 \pm 9$ & $448 \pm 6$ \\
0.1 & $435 \pm 21$ & $486 \pm 14$ & $478 \pm 11$ & $489 \pm 42$ \\
0 (cell control) & $428 \pm 15$ & $468 \pm 9$ & $459 \pm 10$ & $437 \pm 5$ \\
\hline
\end{tabular}


Table 2. Antiviral activity of FI6-IgG1 antibodies and the FI6-IgA1 dimer as inhibitors of the replication of various virus subtypes in MDCK cell culture

\begin{tabular}{|c|c|c|c|c|c|c|c|c|c|c|c|}
\hline \multirow{2}{*}{$\begin{array}{l}\text { Antibody } \\
\text { sample }\end{array}$} & \multirow{2}{*}{ Virus } & \multicolumn{8}{|c|}{$\begin{array}{c}\operatorname{logTCID}_{50} / 0.2 \mathrm{~mL}^{*} \text { at the concentration of antibodies } \\
\text { in the culture medium, } \mu \mathrm{g} / \mathrm{mL}\end{array}$} & \multirow{2}{*}{$\begin{array}{r}\mathrm{IC}_{50} \\
\mu \mathrm{g} / \mathrm{mL}\end{array}$} & \multirow[t]{2}{*}{ SI } \\
\hline & & 0 & 0.1 & 0.3 & 1.0 & 3.0 & 10.0 & 30.0 & 100.0 & & \\
\hline \multirow{6}{*}{ FI6-IgG1 } & $\begin{array}{l}\text { A/California/07/09 } \\
\text { (H1N1)pdm09 }\end{array}$ & 6.5 & 5.5 & 5.5 & 4.5 & $<2.5$ & $<2.5$ & $\mathrm{~N} / \mathrm{T}^{* *}$ & $\mathrm{~N} / \mathrm{T}^{* *}$ & 0.25 & $>400$ \\
\hline & A/Aichi/2/68 (H3N2) & 7.0 & $\mathrm{~N} / \mathrm{T}^{* *}$ & $\mathrm{~N} / \mathrm{T}^{* *}$ & $\mathrm{~N} / \mathrm{T}^{* *}$ & 6.0 & 6.0 & 6.0 & 6.0 & 100 & 1 \\
\hline & $\begin{array}{l}\text { A/PuertoRico/8/34 } \\
\text { (H1N1) }\end{array}$ & 6.0 & 5.0 & 4.0 & 2.5 & $<2.5$ & $<2.5$ & $<2.5$ & $<2.5$ & 0.1 & $>1000$ \\
\hline & $\begin{array}{l}\text { A/mallard/Pennsylva- } \\
\text { nia/10218/84 (H5N2) }\end{array}$ & 6.0 & 4.5 & 4.0 & 2.5 & $<2.5$ & $<2.5$ & $\mathrm{~N} / \mathrm{T}^{* *}$ & $\mathrm{~N} / \mathrm{T}^{* *}$ & $<0.1$ & $>1000$ \\
\hline & A/Anhui/1/13 (H7N9) & 7.5 & 7.5 & 7.5 & 7.5 & 7.5 & 7.5 & $\mathrm{~N} / \mathrm{T}^{* *}$ & $\mathrm{~N} / \mathrm{T}^{* *}$ & $>100$ & 1 \\
\hline & B/Malaysia/2506/04 & 7.5 & $\mathrm{~N} / \mathrm{T}^{* *}$ & $\mathrm{~N} / \mathrm{T}^{* *}$ & $\mathrm{~N} / \mathrm{T}^{* *}$ & 7.5 & 7.5 & 7.5 & 7.5 & $>100$ & 1 \\
\hline \multirow{6}{*}{$\begin{array}{l}\text { FI6-IgA1 } \\
\text { dimer }\end{array}$} & $\begin{array}{l}\text { A/California/07/09 } \\
\text { (H1N1)pdm09 }\end{array}$ & 6.5 & 6.0 & 6.5 & 5.5 & 4.5 & $<2.5$ & $\mathrm{~N} / \mathrm{T}^{* *}$ & $\mathrm{~N} / \mathrm{T}^{* *}$ & 0.5 & $>200$ \\
\hline & A/Aichi/2/68 (H3N2) & 6.5 & $\mathrm{~N} / \mathrm{T}^{* *}$ & $\mathrm{~N} / \mathrm{T}^{* *}$ & $\mathrm{~N} / \mathrm{T}^{* *}$ & 6.0 & 6.0 & 5.5 & 6.0 & $>100$ & 1 \\
\hline & $\begin{array}{l}\text { A/PuertoRico/8/34 } \\
\text { (H1N1) }\end{array}$ & 6.0 & 4.5 & 4.0 & 2.5 & $<2.5$ & $<2.5$ & $<2.5$ & $<2.5$ & $<0.1$ & $>1000$ \\
\hline & $\begin{array}{l}\text { A/mallard/Pennsylva- } \\
\text { nia/10218/84 (H5N2) }\end{array}$ & 6.0 & 6.0 & 5.0 & 5.0 & 4.0 & $<2.5$ & $\mathrm{~N} / \mathrm{T}^{* *}$ & $\mathrm{~N} / \mathrm{T}^{* *}$ & 0.5 & $>200$ \\
\hline & A/Anhui/1/13 (H7N9) & 7.5 & 7.5 & 7.5 & 7.5 & 7.5 & 7.5 & $\mathrm{~N} / \mathrm{T}^{* *}$ & $\mathrm{~N} / \mathrm{T}^{* *}$ & $>100$ & 1 \\
\hline & B/Malaysia/2506/04 & 7.5 & $\mathrm{~N} / \mathrm{T}^{* *}$ & $\mathrm{~N} / \mathrm{T}^{* *}$ & $\mathrm{~N} / \mathrm{T}^{* *}$ & 7.5 & 7.0 & 7.5 & 7.5 & $>100$ & 1 \\
\hline Infliximab & $\begin{array}{l}\text { A/PuertoRico/8/34 } \\
\text { (H1N1) }\end{array}$ & 5.5 & $\mathrm{~N} / \mathrm{T}^{* *}$ & $\mathrm{~N} / \mathrm{T}^{* *}$ & 5.5 & 5.5 & 5.5 & 5.5 & 5.5 & $>100$ & 1 \\
\hline
\end{tabular}

* A smaller value of the infectious activity $\left(\log _{\mathrm{TC}} \mathrm{ID}_{50}\right)$ corresponds to a smaller amount of the virus. ${ }^{* *} \mathrm{~N} / \mathrm{T}$ is not tested.

Table 3. Antiviral activity of oseltamivir carboxylate in vitro system (in MDCK cells)

\begin{tabular}{|c|c|c|c|c|c|c|c|}
\hline \multirow{2}{*}{ Virus } & \multicolumn{5}{|c|}{$\operatorname{logTCID}{ }_{50} / 0.2 \mathrm{~mL}$ at the oseltamivir concentration, $\mu \mathrm{g} / \mathrm{mL}$} & \multirow{2}{*}{$\begin{array}{c}\mathrm{IC}_{50} \\
\mu \mathrm{g} / \mathrm{mL}\end{array}$} & \multirow[b]{2}{*}{ SI } \\
\hline & 0 & 0.01 & 0.03 & 0.10 & 0.30 & & \\
\hline $\begin{array}{l}\text { A/California/07/09 } \\
\text { (H1N1)pdm09 }\end{array}$ & $7.5 \pm 0.0$ & $7.5 \pm 0.0$ & $6.5 \pm 0.0$ & $4.0 \pm 0.5$ & $2.5 \pm 0.0$ & 0.008 & $>125$ \\
\hline A/Aichi/2/68 (H3N2) & $6.0 \pm 0.5$ & $6.0 \pm 0.5$ & $5.5 \pm 0.0$ & $3.5 \pm 0.0$ & $2.0 \pm 0.5$ & 0.013 & $>77$ \\
\hline A/PuertoRico/8/34 (H1N1) & $7.5 \pm 0.0$ & $7.5 \pm 0.0$ & $7.0 \pm 0.5$ & $5.0 \pm 0.5$ & $3.0 \pm 0.5$ & 0.003 & $>333$ \\
\hline $\begin{array}{l}\text { A/mallard/Pennsylva- } \\
\text { nia/10218/84 (H5N2) }\end{array}$ & $7.0 \pm 0.5$ & $6.0 \pm 0.5$ & $5.5 \pm 0.0$ & $4.5 \pm 0.0$ & $3.0 \pm 0.5$ & 0.012 & $>83$ \\
\hline B/Malaysia/2506/04 & $6.5 \pm 0.5$ & $6.5 \pm 0.0$ & $6.0 \pm 0.5$ & $5.0 \pm 0.5$ & $3.5 \pm 0.0$ & 0.026 & $>38$ \\
\hline
\end{tabular}

characteristics of the recombinant antibodies are retained, including those of the IgA1 isotype dimer.

\section{Study of the Antibody Binding Specificity to Infected MDCK Cells (Cell - ELISA)}

Our experiments showed that the FI6-IgG1 antibodies and the FI6-IgA1 dimers specifically bind to MDCK cells infected with influenza virus, whereas the infliximab antibodies used as a negative control do not interact with them. The concentration dependences of the binding of the IgG1 and IgA1 antibody isotypes with the infected cells (Fig. 3) are almost the same as those for strains of the influenza A virus of the different subtypes that we studied. Both $\operatorname{IgG} 1$ and IgA1 were equally efficient in binding cells infected with the A/PR/8/1934 (H1N1) and A/California/07/2009 (H1N1)pdm09 influenza viruses (phylo- 

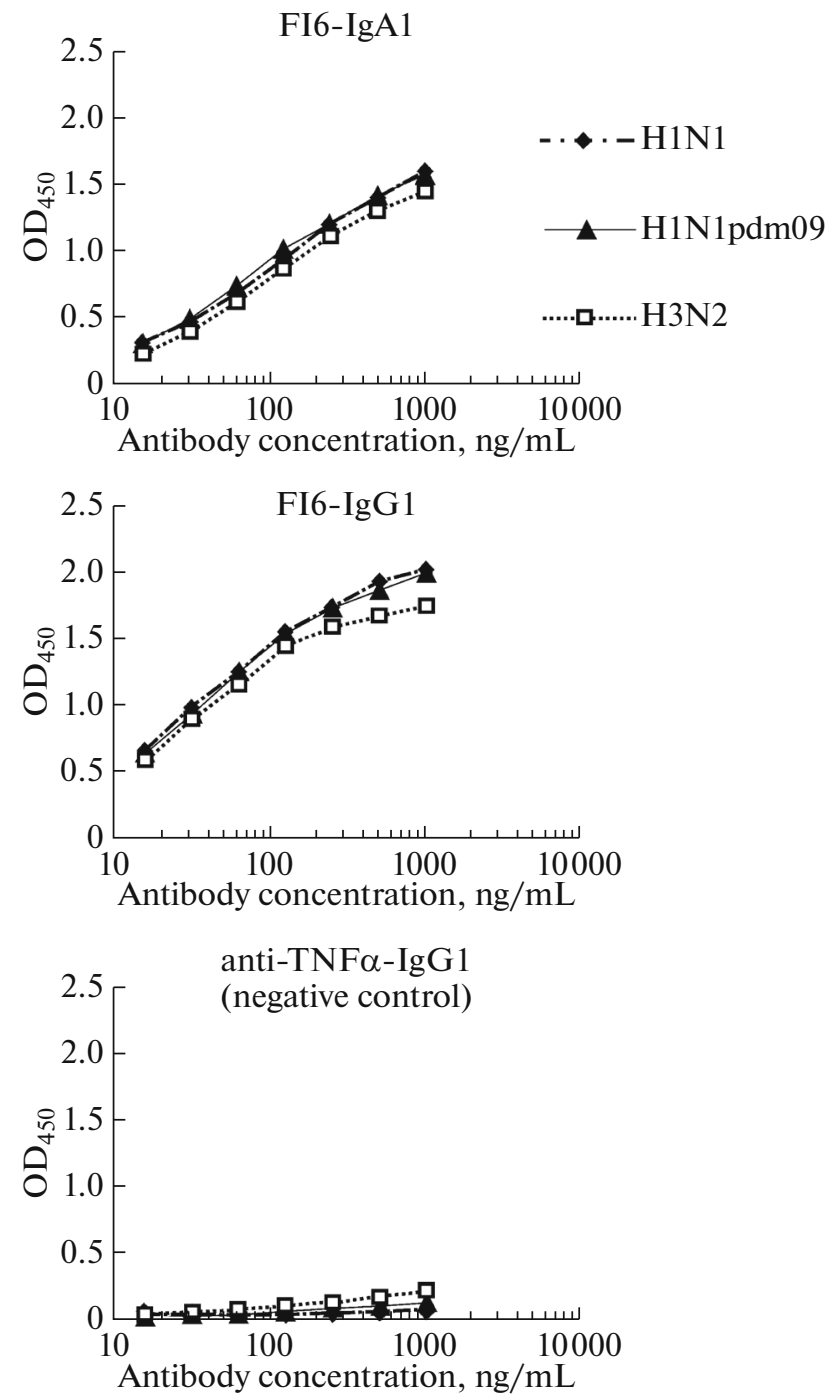

Fig. 3. Specificity of the interactions of FI6-IgA1 dimer and FI6-IgG1 with cells infected with influenza A viruses of different subtypes (in-cell ELISA). The negative control was anti-TNF $\alpha$-IgG1 antibody (infliximab). Designations of strains: H1N1 is A/PuertoRico/8/34 (H1N1); (H1N1)pdm09 is $\mathrm{A} /$ California/07/09 (H1N1)pdm09; and $\mathrm{H} 3 \mathrm{~N} 2$ is A/Aichi/2/68 (H3N2).

genetic group I) and cells infected with the A/Aichi/2/1968 (H3N2) influenza virus (phylogenetic group II). Results of the study are shown in Fig. 3, which shows that antibodies (both $\mathrm{gG} 1$ and IgA1) interact with MDCK cells that are infected with influenza A viruses of the two studied subtypes, H1N1 and H3N2, from which we can infer that the antibodies are cross reactive.

\section{DISCUSSION}

After the subsequent stages of transfection and selection, we chose the eight producer clones with the best indicators of productivity and growth. These are the producers of monomers of the A1C6, A1D8, A2D2, and A2F2 antibodies and dimers of the JA1C6, JA1D8, JA2D2, and JA2F2 antibodies. The comparison showed that the indicators of productivity and growth of the dimeric IgA1-isotype antibodies are approximately twice as high as the respective indicators of the monomeric forms. It also showed that, according to the above-mentioned indicators, both monomeric and dimeric forms of the IgA1-isotype antibodies are twice as good as both isoforms of the IgA2m1-type antibodies.

A significant difference was also observed in the growth of suspension cultures of the resulting cell lines that produce the dimers and monomers of the IgA1 and $\operatorname{IgA} 2 \mathrm{~m} 1$ isotypes in spinner flasks. When the number of plasmid copies was increased by methotrexate, the growth of cell lines that produced monomeric FI6-IgA1 slowed down, the antibody aggregation in the culture became enhanced, and the culture itself lost its stability during a prolonged cultivation. The increased aggregate formation and the decrease in the productivity are probably associated with the glycosylation of antibodies. For instance, $\mathrm{CHO}$ cells are known to produce triantennary glycans in a molecule of the IgA monomer, whereas, in the animal serum, the glycan of these antibodies is in the biantennary form [22]. Unlike monomer-producing cultures, the suspension cultures of the cell lines that produce dimers demonstrate as dynamic and stable growth during production; these cultures are characterized by high viability and the capacity to maintain continued growth and productivity for more than 20 days. Cell cultures that produce dimeric FI6-IgA1 antibodies didn't form visible aggregates. All of the above-mentioned characteristics of the cell lines that produce IgA1 dimers are similar to those of the producers of IgG1. This similarity is likely associated with the fact that the disulfide bonds between the $\mathrm{H}$ - and L-chains are similar in IgA1 and IgG1 but not in $\operatorname{IgA} 2 \mathrm{~m} 1$. Thus, a stable cell line (clone A1C6 $+\mathrm{J}$ ) that produced dimeric FI6-IgA1 antibodies was selected for further in vitro experiments, whereas the FI6-IgG1 antibodies were used for the comparison.

Before evaluating the antiviral activity of the obtained recombinant antibodies, we analyzed their possible toxicity to MDCK cells and showed that the FI6-IgA1 dimer and the FI6-IgG1 antibody at the tested concentrations have no effect on the proliferative activity of these cells. The study showed that the dimeric form of FI6-IgA1 and the FI6-IgG1 antibody neutralize the A/PuertoRico/8/34 influenza virus at the concentration similar to that of the original antibody and inhibit the infection of MDCK cells with influenza A viruses of various subtypes, although the greatest effect was observed in the strains of $\mathrm{H} 1 \mathrm{~N} 1$ and H5N2 subtypes (SI > 1000). The IC50 and SI values obtained for the FI6-IgG1 and FI6-IgA1 antibodies are typical for the preparations with a high antiviral activity. The A/Aichi/2/68 (H3N2), A/Anhui/1/13 
(H7N9), and B/Malaysia/2506/04 influenza viruses, however, were nearly insensitive to the action of these antibodies. When analyzing the specificity of the interaction between antibodies and infected cells by cell-ELISA, we found that the FI6-IgG1 antibodies and the dimeric form of FI6-IgA1 bind specifically to influenza viruses of subtypes H1N1 (phylogenetic group I) and $\mathrm{H} 3 \mathrm{~N} 2$ (phylogenetic group II). The obtained recombinant IgG1-isotype antibodies and the IgA1-isotype dimers have cross reactivity to influenza viruses of both phylogenetic groups.

\section{ACKNOWLEDGMENTS}

We thank A.V. Petrov (State Research Institute of Highly Pure Biopreparations of the Federal Medical and Biological Agency of Russia, Russia) for providing infliximab. We thank V.S. Rybchenko (Faculty of Biology, Moscow State University) for helping to prepare the article.

This work was supported by the Ministry of Education and Science of the Russian Federation (contract no. 14.607.21.0060) in the Federal Targeted Program for Research and Development in Priority Areas of the Development of the Russian Scientific and Technological Complex for 2014-2020 (Project Identification Number RFMEFI60714X0060).

\section{REFERENCES}

1. Juncuera L.C., Carneiro J. 2003. Basic Histology. McGraw-Hill. ISBN 0-8385-0590-2.

2. Holmgren J., Czerkinsky C. 2005. Mucosal immunity and vaccines. Nat. Med. 11 (4s), 45-53.

3. Torano A., Tsuzukida Y., Liu Y.S., et al. 1977. Location and structural significance of the oligosaccharides in human Ig-A1 and IgA2 immunoglobulins. Proc. Natl. Acad. Sci. U. S. A. 74, 2301-2305.

4. Mattu T.S., Pleass R.J., Willis A.C., et al. 1998. The glycosylation and structure of human serum IgA1, Fab and Fc regions and the role of N-glycosylation on Fc alphareceptor interactions. J. Biol. Chem. 273, 2260-2272.

5. Yoo E.M., Yu Li J, Wims L.A., et al. 2010. Differences in N-glycan structures found on recombinant IgA1 and $\mathrm{IgA} 2$ produced in murine myeloma and $\mathrm{CHO}$ cell lines. MAbs. 2, 320-334.

6. Ekiert D.C., Wilson I.A. 2012. Broadly neutralizing antibodies against influenza virus and prospects for universal therapies. Curr. Opin. Virol. 2, 134-141.

7. Van Riet E., Ainai A., Suzuki T., et al. 2012. Mucosal IgA responses in influenza virus infections; thoughts for vaccine design. Vaccine. 30, 5893-5900.

8. Muramatsu M., Yoshida R., Miamoto H., et al. 2013. Heterosubtypic antiviral activity of hemagglutinin-specific antibodies induced by intranasal immunization with inactivated influenza viruses in mice. PLoS ONE. 8, e71534.

9. Ambrose C.S., Luke C., Coelingh K. 2008. Influenza current status of live attenuated influenza vaccine in the United States for seasonal and pandemic influenza. Influenza Other Respir. Viruses. 2, 193-202.

10. Barría M.I., Garrido J.L., Stein C., et al. 2013. Localized mucosal response to intranasal live attenuated influenza vaccine in adults. J. Infect. Dis. 207, 115-124.

11. Belshe R.B., Gruber W.C., Mendelman P.M., et al. 2000. Correlates of immune protection induced by live, attenuated, cold-adapted, trivalent, intranasal influenza virus vaccine. J. Infect. Dis. 181, 1133-1137.

12. Lohse S., Derer S., Beyer T., et al. 2011. Recombinant dimeric IgA epidermal growth factor receptor mediate effective tumor cell killing. J. Immunol. 186, 37703778.

13. Corti D., Voss J., Gamblin S.J., et al. (2011. A neutralizing antibody selected from plasma cells that binds to group 1 and group 2 influenza A hemagglutinins. Science. 333, 850-856.

14. Argentova V.V., Aliev T.A., Toporova V.A. 2016. Acta Naturae. 2, 140. http://rcpcm.org/wp-content/uploads/ 2016/10/AbstractBook_Vol2.pdf.

15. Argentova V.V., Aliev T.K., Toporova V.A., et al. 2017. Studies on the influence of different designs of eukaryotic vectors on the expression of recombinant IgA. Moscow Univ. Biol. Sci. Bull. 72 (2), 763-768.

16. Mosmann T. 1983. Rapid colorimetric assay for cellular growth and survival: Application to proliferation and cytotoxicity assays. J. Immunol. Methods. 65, 55-63.

17. Reed L.J., Muench H. 1938. A simple method of estimating fifty percent endpoints. Am. J. Hyg. 27, 493497.

18. Guan H., Nuth M., Zhukovskaya N., et al. 2014. A novel target and approach for identifying antivirals against molluscum contagiosum virus. Antimicrob. Agents Chemother. 58, 7383-7389.

19. Won J.-N., Lee S.-Y., Song D.-S., Poo H. 2013. Antiviral activity of the plant extracts from Thuja orientalis, Aster spathulifolius, and Pinus thunbergii against influenza virus A/PR/8/34. J. Microbiol. Biotechnol. 23, 125-130.

20. Lin X., Zhou J., Zhang Y., et al. 2009. Oseltamivir boosts 2009 H1N1 virus infectivity in vitro. Biochem. Biophys. Res. Commun. 390, 1305-1308.

21. Bout A., Halford D., Jones A. 2005. Patent No. EP 1508576 A1. February 23, 2005.

22. Galabov A.S., Mileva M., Simeonova L., Gegova G. 2015. Combination activity of neuraminidase inhibitor oseltamivir and $\alpha$-tocopherol in influenza virus $A$ (H3N2) infection in mice. Antivir. Chem. Chemother. 3-4, 83-91.

Translated by Yu. Modestova 